\title{
Circadian rhythms of GIP and GLP1 in glucose-tolerant and in type 2 diabetic patients after biliopancreatic diversion
}

\author{
G. Mingrone • G. Nolfe • G. Castagneto Gissey • \\ A. Iaconelli • L. Leccesi • C. Guidone • G. Nanni • \\ J. J. Holst
}

Received: 27 October 2008 / Accepted: 14 January 2009/Published online: 20 February 2009

(C) Springer-Verlag 2009

\begin{abstract}
Aims/hypothesis We tested the hypothesis that the reversibility of insulin resistance and diabetes observed after biliopancreatic diversion (BPD) is related to changes in circadian rhythms of gastrointestinal hormones.

Methods Ten morbidly obese participants, five with normal glucose tolerance (NGT) and five with type 2 diabetes, were studied before and within 2 weeks after BPD. Withinday variations in glucose-dependent insulinotropic polypeptide (GIP) and glucagon-like peptide 1 (GLP1) levels were assessed using a single cosinor model. Insulin sensitivity was assessed by euglycaemic-hyperinsulinaemic clamp.

Results Basal GLP1 relative amplitude (amplitude/ mesor $\times 100$ ) was $25.82-4.06 \%$ in NGT; it increased to
\end{abstract}

G. Mingrone $(\bowtie) \cdot$ A. Iaconelli $\cdot$ L. Leccesi $\cdot$ C. Guidone Department of Internal Medicine, Università Cattolica S. Cuore, Largo A. Gemelli, 8,

00168 Rome, Italy

e-mail: gmingrone@rm.unicatt.it

G. Nolfe

CNR Institute of Cybernetics 'E. Caianiello',

Pozzuoli, Italy

G. Castagneto Gissey

Department of Economics, University of Kent,

Canterbury, UK

\section{G. Nanni}

Department of Surgery, Università Cattolica S. Cuore, Rome, Italy

\section{J. J. Holst}

Department of Biomedical Sciences, Panum Institute,

University of Copenhagen,

Copenhagen, Denmark
41.38-4.32\% after BPD but was unchanged in diabetic patients. GLP1 and GIP mesor were shifted in time after surgery in diabetic patients but not in NGT participants. After BPD, the GLP1 AUC significantly increased from $775 \pm 94$ to $846 \pm 161 \mathrm{pmol} \mathrm{l}^{-1} \mathrm{~min}$ in NGT, whereas GIP AUC decreased significantly from $1,373 \pm 565$ to $513 \pm 186 \mathrm{pmol}^{-1} \mathrm{~min}$ in diabetic patients. Two-way ANOVA showed a strong influence of BPD on both GIP $(p=0.010)$ and GLP1 AUCs $(p=0.033)$, which was potentiated by the presence of diabetes, particularly for GIP $(\mathrm{BPD} \times$ diabetes, $p=0.003)$. Insulin sensitivity was markedly improved $(p<0.01)$ in NGT (from $9.14 \pm$ 3.63 to $36.04 \pm 8.55 \mu \mathrm{mol}[\mathrm{kg} \text { fat-free mass }]^{-1} \mathrm{~min}^{-1}$ ) and diabetic patients (from $9.49 \pm 3.56$ to $38.57 \pm 4.62 \mu \mathrm{mol}$ [kg fat-free mass $]^{-1} \min ^{-1}$ ).

Conclusions/interpretation An incretin circadian rhythm was shown for the first time in morbid obesity. The effect of BPD on the $24 \mathrm{~h}$ pattern of incretin differed between NGT and diabetic patients. GLP1 secretion impairment was reversed in NGT and could not be overcome by surgery in diabetes. On the other hand, GIP secretion was blunted after the operation only in diabetic patients, suggesting a role in insulin resistance and diabetes.

Keywords Bariatric surgery · Circadian rhythm · GIP. GLP1 Morbid obesity
Abbreviations
BPD Biliopancreatic diversion
FFM Fat-free mass
GIP Glucose-dependent insulinotropic polypeptide
GLP1 Glucagon-like peptide 1
NGT Normal glucose tolerance
RYGB Roux-en-Y gastric bypass 


\section{Introduction}

It has been clearly demonstrated that in diabetes the glucagon-like peptide 1 (GLP1) response is blunted [1] and that the response of pancreatic beta cells to glucosedependent insulinotropic polypeptide (GIP) is severely impaired [2]. These and other observations have strengthened the hypothesis, advanced by Nauck et al. [3], that the beta cell incompetence observed in diabetes is, at least partially, due to an impaired effect of incretin.

The prevalence of obesity has recently reached epidemic proportions [4] in both Western and developing countries, with morbid obesity accounting for about 9\% [5] of the whole obese population. On the other hand, obesity and type 2 diabetes are so strictly associated that the term 'diabesity' has been coined [6]. Because of such interdependence, it is difficult to discriminate between the separate roles of obesity and glucose tolerance in the effect of incretins on beta cell function. Recently, however, some light has been shed on this topic, showing that obesity and glucose tolerance each attenuate the effect of incretin and the GLP1 response independently of one another [7].

Lifestyle intervention programmes and pharmacotherapy fail to maintain long-term weight loss, particularly in severe obesity [8], whereas bariatric surgery is effective and associated with a significant reduction in mortality [9]. Relatively few data are available concerning the effect of bariatric surgery on incretin secretion [10-15] and, at least to our knowledge, no data exist regarding the response of incretin to multiple meals.

We have previously demonstrated that insulin resistance and type 2 diabetes are reversible after malabsorptive bariatric surgery [16-18]. However, we are far from understanding the mechanisms involved. In a previous study of ours [11], the time course of GIP and GLP1 after an OGTT showed a reduction in the GIP AUC and an increase in the GLP1 AUC early after the bariatric operation in obese diabetic people. In the present study, however, the fluctuations of incretins were studied over $24 \mathrm{~h}$ in near-physiological conditions.

To check the hypothesis that the reversibility of insulin resistance and diabetes observed after biliopancreatic diversion (BPD) is related to changes in the circadian rhythm of gastrointestinal hormones, the $24 \mathrm{~h}$ profiles of GLP1 and GIP were studied in ten morbidly obese participants, five with normal glucose tolerance (NGT) and five with type 2 diabetes, before and within 2 weeks after BPD.

\section{Methods}

Study protocol Ten morbidly obese women undergoing BPD were studied. Five were aged $44.0 \pm 8.6$ years and had
NGT as assessed by OGTT, and five were aged $42.6 \pm$ 5.7 years (age difference not significant) and had type 2 diabetes mellitus with an onset 2-5 years before the study began. The glycosylated haemoglobin value was $7.2-9.0 \%$. All the diabetic patients were being treated with oral hypoglycaemic agents. Immediately after BPD, medical therapy for diabetes was stopped.

All participants underwent the metabolic study at baseline and within 2 weeks after the bariatric surgery, spending $24 \mathrm{~h}$ (starting at 08:00 hours) on the metabolic ward. During this period, four meals were administered. The total daily energy intake of $125.6 \mathrm{~kJ} / \mathrm{kg}$ fat-free mass (FFM) was distributed as follows: $13.4 \%$ was taken at breakfast (09:00 hours), $36 \%$ at 12:00-13:00 hours, $16.4 \%$ as an afternoon snack (16:00-16:30 hours) and $34.2 \%$ at dinner (19:00-20:00 hours). The average diet composition was $16.9 \%$ of energy as protein, $34.6 \%$ fat and $48.5 \%$ carbohydrates.

Blood samples were drawn from a central venous catheter each hour for the measurement of glucose, insulin, GIP and GLP1 concentrations.

The study protocol was approved by the Institutional Ethics Committee of the Catholic University of Rome. The nature and purpose of the study were carefully explained to all participants before they provided their written consent to participate.

BPD and body composition The BPD operation was as described previously [11]. Body weight was measured to the nearest $0.1 \mathrm{~kg}$ with a beam scale and height to the nearest $0.5 \mathrm{~cm}$ using a stadiometer (Holatin, Crosswell, UK). Total body water was measured by the labelled water dilution method and FFM and fat mass were calculated as described previously [11].

Euglycaemic-hyperinsulinaemic clamp Peripheral insulin sensitivity was evaluated by the euglycaemic-hyperinsulinaemic clamp technique [19] at baseline and within 2 weeks after surgery. Small boluses of insulin were administered subcutaneously to diabetic patients to achieve euglycaemia. Glucose disposal ( $M$ value) was calculated from the exogenous glucose infusion rate during the last $40 \mathrm{~min}$ of the $2 \mathrm{~h}$ clamp after correction for changes in glucose concentration in a total distribution volume of $250 \mathrm{ml} / \mathrm{kg}$. Whole-body glucose disposal was normalised per $\mathrm{kg}$ FFM $\left(M / \mathrm{kg}_{\mathrm{FFM}}\right)$.

Analytical methods Blood samples were drawn into EDTAevacuated tubes. The plasma was immediately separated by centrifugation at $4^{\circ} \mathrm{C}$ and stored at $-80^{\circ} \mathrm{C}$ until assay. The samples were not thawed until hormone assays were performed.

Plasma glucose was measured by the glucose oxidase method (Beckman, Fullerton, CA, USA). 
Plasma insulin was assayed by microparticle enzyme immunoassay (Abbott, Pasadena, CA, USA) with a sensitivity of $6 \mathrm{pmol} / \mathrm{l}$ and an intra-assay $\mathrm{CV}$ of $6.6 \%$.

GIP and GLP1 concentrations in plasma were measured after extraction of plasma with $70 \%$ ethanol (vol./vol., final concentration) according to techniques developed at the Panum Institute, University of Copenhagen [20, 21].

Rhythm analysis To compare intra-day time series of insulin, GIP and GLP1 obtained in the basal condition and after bariatric surgery, the following time averages were estimated:

$\frac{1}{T} \int_{0}^{T} y(t) d t \equiv\langle y(t)\rangle \quad$ mean level

$\frac{1}{T} \int_{0}^{T} y^{2}(t) d t \equiv\left\langle y^{2}(t)\right\rangle \quad$ mean square (or intensity)

where $T=24 \mathrm{~h}$. The mean intensity is proportional to the mean power of the time series.

Single cosinor models of the form:

$z(t)=M+A \cos \left(\frac{2 \pi t}{t}+\varphi\right)+e(t)$

were used to model the variation in measured hormonal levels as a function of time $t$ (hours). $z(t)$ and $e(t)$ are the measured concentration and error between the cosinor model and the measurement, respectively. The variable $M$ denotes the mesor (value about which the variation occurs), $A$ the amplitude (distance from mesor to peak) and $\varphi$ (radians) the acrophase (the time of occurrence of the peak equals $\varphi T / 2 \pi) . T$ is the period of $24 \mathrm{~h}$.

For a fixed value of $T$ and known values of $t$, simple rearrangement of the model using trigonometric identities gives a linear model in the coefficients, $M, \gamma$ and $\beta$,

$z(t)=M+\gamma \cos \left(\frac{2 \pi t}{T}\right)+\beta \sin \left(\frac{2 \pi t}{T}\right)+e(t)$

which can be fitted using conventional least-squares methods. Individual single cosinor models were fitted using least squares. The idea that the data are better explained by the null hypothesis (H0) of a constant value (mesor) than $(\mathrm{H} 1)$ a sine was tested using a likelihood ratio $(F)$ test: reject $\mathrm{H} 0$ for large values of GIP and GLP1. An $F$ ratio $F_{2,69}(0.95)$ of 3.13 was considered significant. A group cosinor model was computed by averaging the coefficients from the individual fits.

Statistical analysis The participants were divided into two groups on the basis of the presence of normal glucose tolerance or diabetes.

Before statistical analysis, normal distribution and homogeneity of the variances were evaluated using Levene's test. Since the hormone data exhibited moderate right skewness, their square roots were taken to normalise the data set.

To determine how the hormonal change was affected by two factors (BPD and diabetes), two-way ANOVA was carried out; the sample size power was computed using $\alpha=0.05$.

Regression analysis and ANOVA for multiple dependent variables by the two factor variables (BPD and diabetes) were obtained by using the general linear model multivariate procedure. Using this general linear model procedure, we tested null hypotheses about the effects of BPD and diabetes factor variables on the means of various groupings of a joint distribution of dependent variables, namely insulin sensitivity ( $M$ value), GIP AUC and GLP1 AUC. The interactions between factors as well as the effects of individual factors were also investigated.

Data are mean \pm SD unless otherwise specified. Statistical significance was assumed at $p<0.05$.

Statistical analyses were performed by using the statistical software package SPSS version 10.0 (SPSS, Chicago, IL, USA).

\section{Results}

As shown in Table 1, body composition did not change significantly in either NGT or diabetic participants after surgery.

Insulin sensitivity was markedly improved after BPD $(p<0.0001)$, both in NGT participants (from $9.14 \pm 3.63$ to

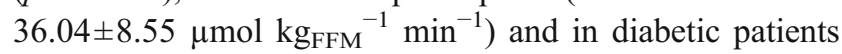
(from $9.49 \pm 3.56$ to $38.57 \pm 4.62 \mu \mathrm{mol} \mathrm{kg} \mathrm{FFM}^{-1} \mathrm{~min}^{-1}$ ). No significant differences from before to after BPD were

Table 1 Patient characteristics

\begin{tabular}{llllll}
\hline Characteristic & \multicolumn{2}{l}{ NGT } & & \multicolumn{2}{l}{ Type 2 diabetes } \\
\cline { 2 - 3 } \cline { 5 - 6 } & Before BPD & After BPD & & Before BPD & After BPD \\
\hline BMI $\left(\mathrm{kg} / \mathrm{m}^{2}\right)$ & $45.4 \pm 6.8$ & $42.8 \pm 6.0$ & & $44.6 \pm 7.9$ & $43.0 \pm 7.1$ \\
FFM $(\mathrm{kg})$ & $76.6 \pm 15.6$ & $74.1 \pm 15.3$ & & $81.0 \pm 18.3$ & $78.5 \pm 18.1$ \\
Fat mass $(\mathrm{kg})$ & $58.6 \pm 12.3$ & $53.6 \pm 7.9$ & & $59.2 \pm 13.0$ & $52.9 \pm 9.5$ \\
\hline
\end{tabular}


a

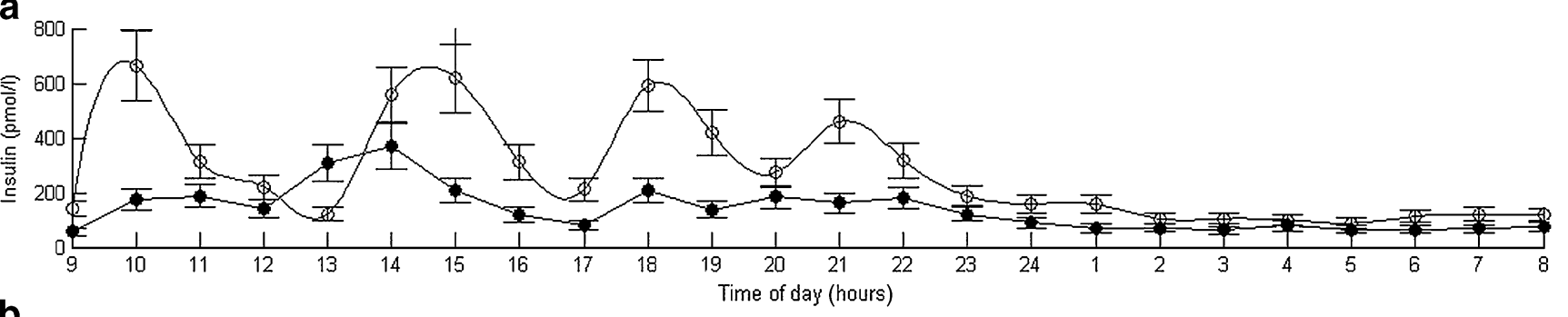

b

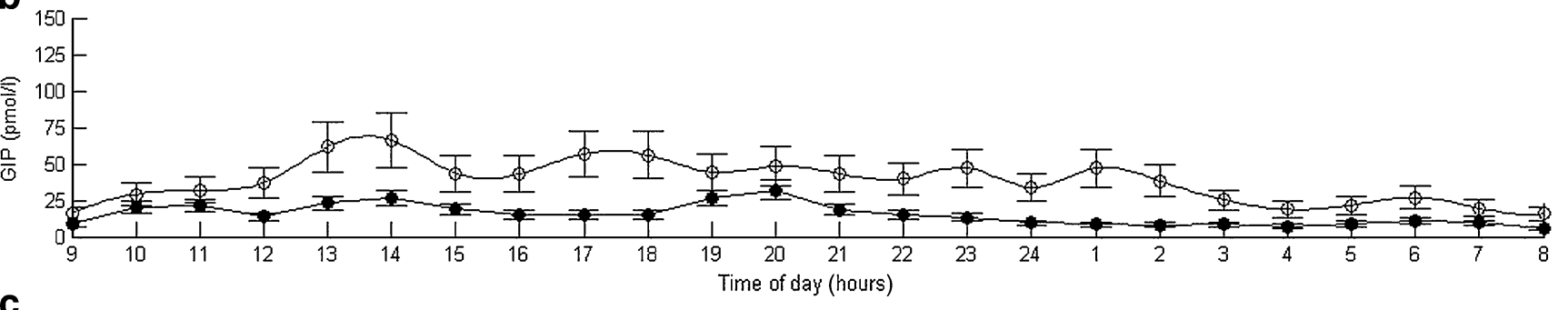

C

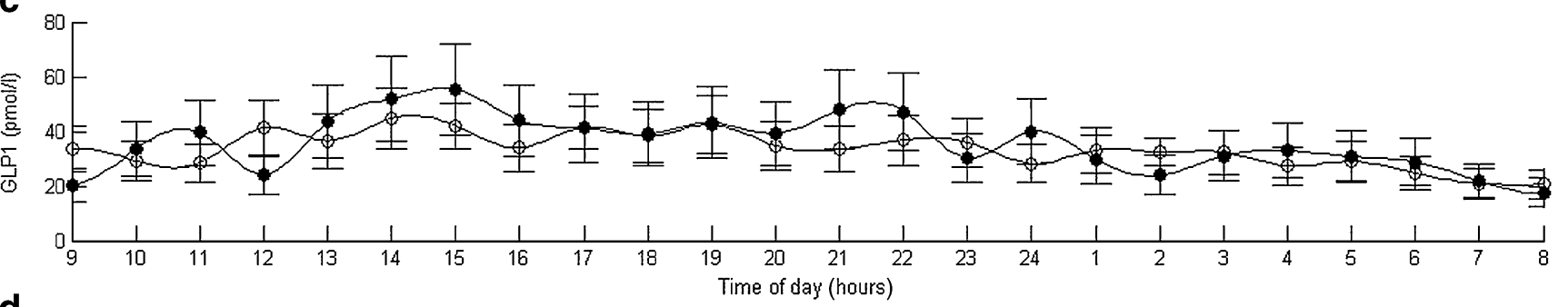

d

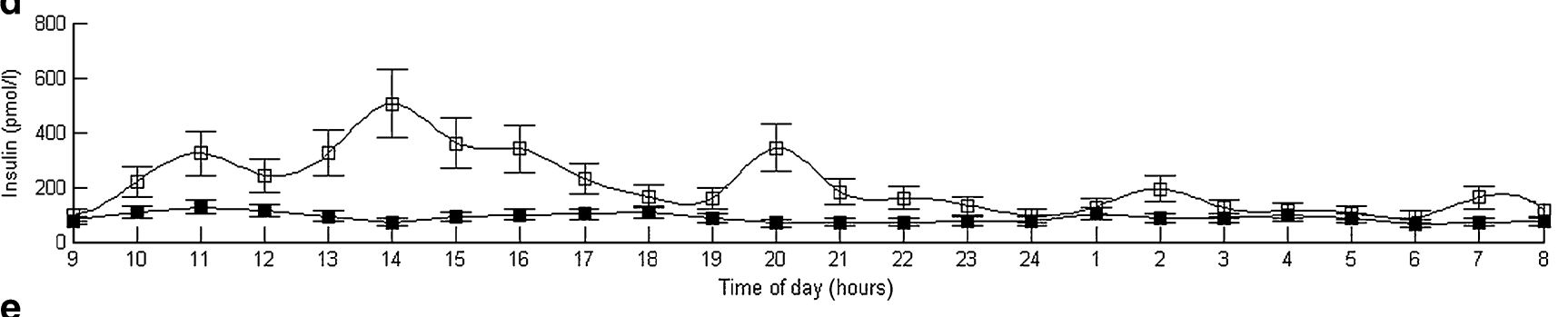

e

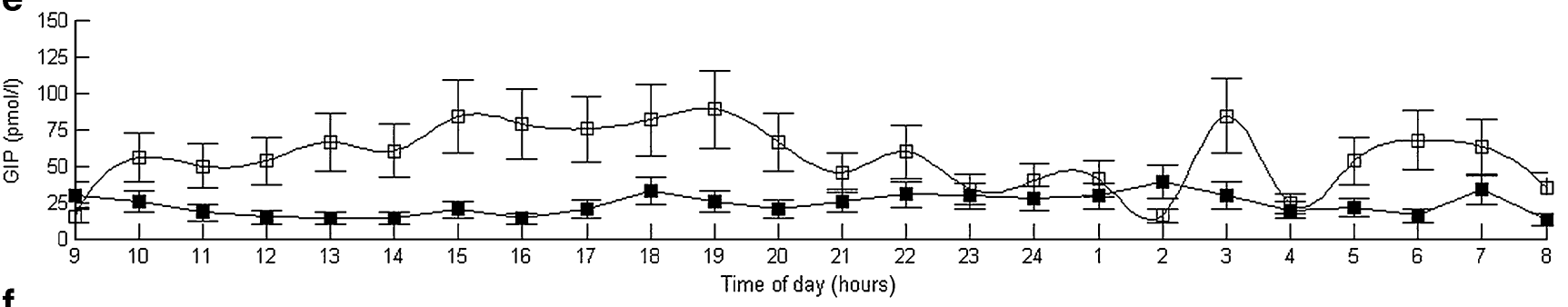

f

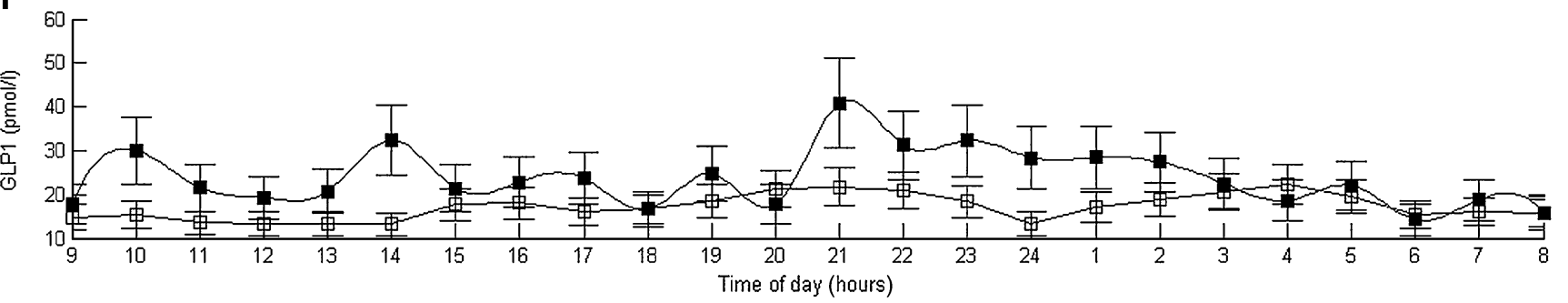

Fig. 1 Time courses of plasma insulin (a, d), GIP (b, e) and GLP1 (c, f) in NGT (circles) and type 2 diabetic (squares) participants before (white symbols) and after (black symbols) BPD. Values are means \pm SEM. Values on the $y$-axes represent time of day in the $24 \mathrm{~h}$ clock. The times of breakfast, lunch, snack and dinner were 09:00-09:30, 12:30-13:00, 16:30-17:00 and 19:30-20:00 hours, respectively. Sleeping time was between 22:30 and 08:00 hours 
Table 2 Cosinor variables and AUC of incretins for NGT and type 2 diabetic participants

\begin{tabular}{|c|c|c|c|c|c|c|c|c|}
\hline \multirow[t]{3}{*}{ Variable } & \multicolumn{4}{|l|}{ NGT } & \multicolumn{4}{|c|}{ Type 2 diabetes } \\
\hline & \multicolumn{2}{|l|}{ GLP1 } & \multicolumn{2}{|l|}{ GIP } & \multicolumn{2}{|l|}{ GLP1 } & \multicolumn{2}{|l|}{ GIP } \\
\hline & Before BPD & After BPD & Before BPD & After BPD & Before BPD & After BPD & Before BPD & After BPD \\
\hline Acrophase $^{\mathrm{a}}$ & $17: 56 \pm 1.08$ & $17: 14 \pm 1.31$ & $18: 30 \pm 1.54$ & $16: 48 \pm 0.19$ & $07: 22 \pm 3.51$ & $11: 14 \pm 2.53$ & $13: 56 \pm 2.42$ & $11: 22 \pm 3.07$ \\
\hline Mesor & $33.41 \pm 3.83$ & $35.54 \pm 6.42$ & $36.77 \pm 15.57$ & $14.85 \pm 2.38$ & $17.59 \pm 1.91$ & $23.14 \pm 5.34$ & $58.64 \pm 23.05$ & $22.41 \pm 7.80$ \\
\hline Amplitude & $8.09 \pm 0.92$ & $14.36 \pm 2.35$ & $20.14 \pm 6.29$ & $8.14 \pm 1.48$ & $4.01 \pm 0.80$ & $9.26 \pm 3.21$ & $21.48 \pm 7.40$ & $7.07 \pm 4.42$ \\
\hline $\begin{array}{l}\text { AUC } \\
\left(\mathrm{pmol} \mathrm{l}^{-1} \mathrm{~min}\right)\end{array}$ & $775 \pm 94$ & $834 \pm 161$ & $670 \pm 215$ & $351 \pm 60$ & $407 \pm 47$ & $539 \pm 133$ & $1,373 \pm 565$ & $513 \pm 186$ \\
\hline
\end{tabular}

${ }^{\mathrm{a}}$ Time of day in $24 \mathrm{~h}$ clock \pm time (h)

observed in plasma insulin levels during the clamp in each group (from $470.4 \pm 37.6$ to $438.0 \pm 17.49 \mathrm{pmol} / \mathrm{l}$ in NGT participants and from $454.8 \pm 27.30$ to $441.6 \pm 13.8 \mathrm{pmol} / \mathrm{l}$ in diabetic participants).

Figure 1 shows the $24 \mathrm{~h}$ concentration averaged profile of each hormone (mean \pm SEM) for diabetic and NGT participants. Visual inspection of the GIP and GLP1 time courses strongly supports the existence of a circadian rhythm. Based on this observation, we tested the hormone data for a periodic signal using single cosinor analysis, assuming a $24 \mathrm{~h}$ period.

a

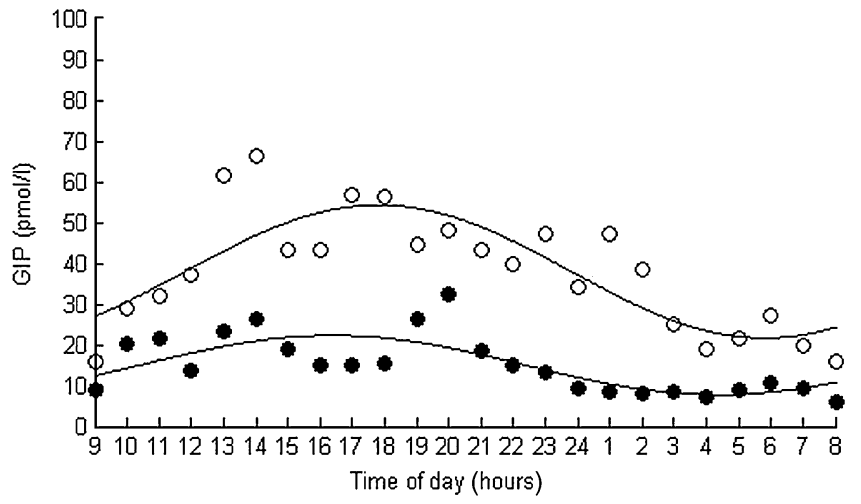

C

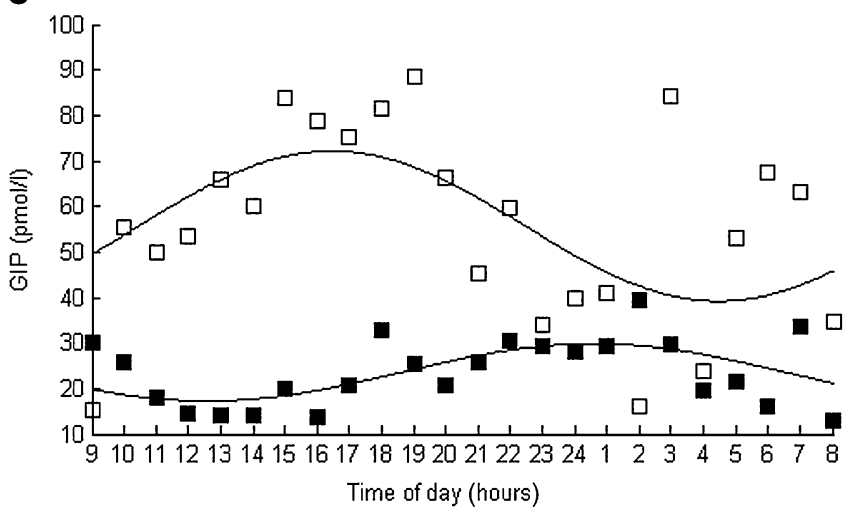

Table 2 summarises the values of the cosinor variables for GLP1 and GIP. The mean \pm SEM percentage relative amplitude (amplitude/mesor $\times 100$ ) of GLP1 was 25.82 \pm $4.06 \%$ in NGT participants before BPD and increased, but not significantly, to $41.38 \pm 4.32 \%$ after BPD. The relative amplitude of GLP1 did not change significantly in diabetic participants. In contrast, the relative amplitude of GIP was reduced more in type 2 diabetic patients (from $41.38 \pm 4.32$ to $25.82 \pm 4.06 \%)$ than in NGT participants $(63.00 \pm 16.27$ to $51.24 \pm 8.26 \%)$.

b

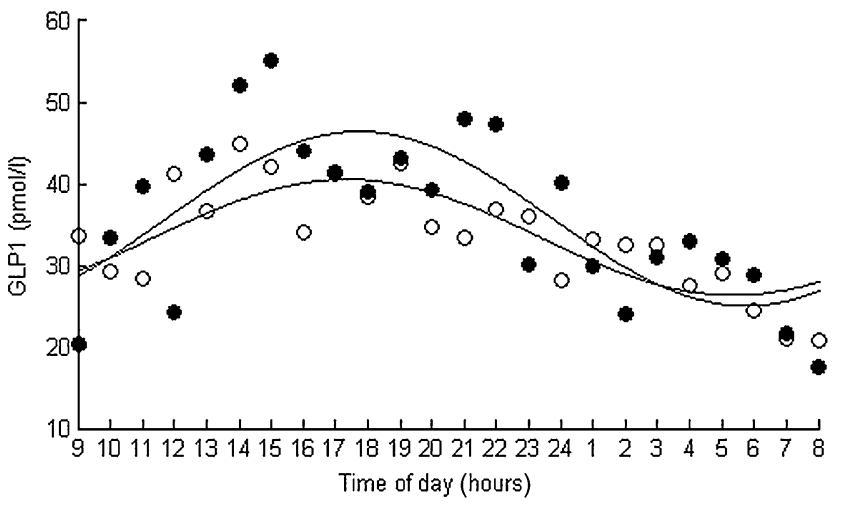

d

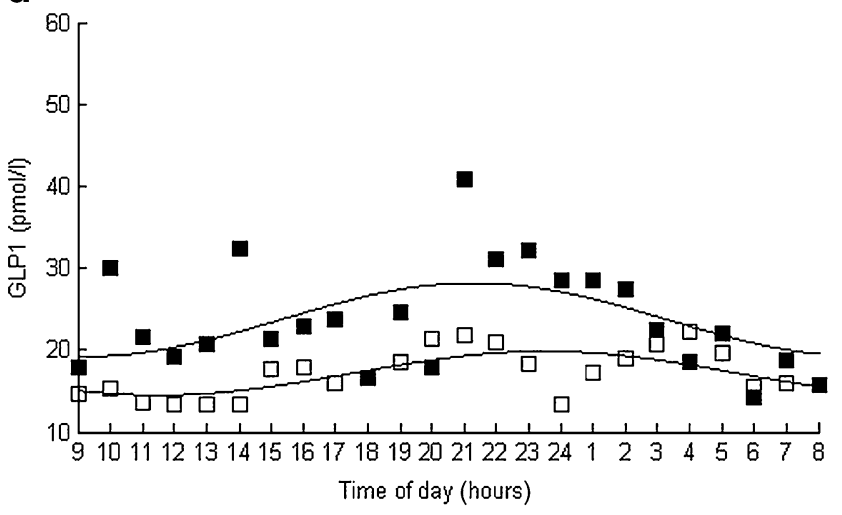

Fig. 2 Estimated cosinor (solid line) before (white symbols) and after (black symbols) BPD in NGT (a, b) and type 2 diabetic participants (c, d). Values on the $y$-axes represent time of day in the $24 \mathrm{~h}$ clock. The symbols are as for Fig. 1 
Table 3 Results of the two-way ANOVA test for relevant measures

\begin{tabular}{|c|c|c|c|}
\hline Factor & $F$ value & $p$ value & Observed power \\
\hline \multicolumn{4}{|c|}{ GIP AUC (pmol $\left.1^{-1} \mathrm{~min}\right)$} \\
\hline BPD & 8.636 & $0.010^{\mathrm{a}}$ & $0.788^{\mathrm{a}}$ \\
\hline Diabetes & 5.064 & $0.043^{\mathrm{a}}$ & $0.543^{\mathrm{a}}$ \\
\hline $\mathrm{BPD} \times$ diabetes & 12.520 & $0.003^{\mathrm{a}}$ & $0.913^{\mathrm{a}}$ \\
\hline \multicolumn{4}{|c|}{ GLP1 AUC (pmol $\left.1^{-1} \min \right)$} \\
\hline BPD & 5.463 & $0.033^{\mathrm{a}}$ & $0.697^{\mathrm{a}}$ \\
\hline Diabetes & 3.734 & 0.071 & \\
\hline $\mathrm{BPD} \times$ diabetes & 7.889 & $0.013^{\mathrm{a}}$ & $0.823^{\mathrm{a}}$ \\
\hline \multicolumn{4}{|c|}{ Insulin AUC (pmol $\left.1^{-1} \mathrm{~min}\right)$} \\
\hline BPD & 10.070 & $0.006^{\mathrm{a}}$ & $0.846^{\mathrm{a}}$ \\
\hline Diabetes & 0.383 & 0.545 & \\
\hline $\mathrm{BPD} \times$ diabetes & 0.101 & 0.755 & \\
\hline \multicolumn{4}{|c|}{ GLP1 acrophase (time of day) } \\
\hline BPD & 4.846 & $0.043^{\mathrm{a}}$ & $0.543^{\mathrm{a}}$ \\
\hline Diabetes & 0.380 & 0.546 & \\
\hline $\mathrm{BPD} \times$ diabetes & 5.926 & $0.027^{\mathrm{a}}$ & $0.628^{\mathrm{a}}$ \\
\hline \multicolumn{4}{|l|}{ GLP1 mesor } \\
\hline BPD & 0.252 & 0.623 & \\
\hline Diabetes & 21.832 & $0.000^{\mathrm{a}}$ & $0.992^{\mathrm{a}}$ \\
\hline $\mathrm{BPD} \times$ diabetes & 0.994 & 0.334 & \\
\hline \multicolumn{4}{|c|}{ Insulin sensitivity $(M)\left(\mu \mathrm{mol} \mathrm{kg}_{\mathrm{FFM}}{ }^{-1} \mathrm{~min}^{-1}\right)$} \\
\hline BPD & 154.672 & $0.000^{\mathrm{a}}$ & $1.000^{\mathrm{a}}$ \\
\hline Diabetes & 1.189 & 0.292 & \\
\hline $\mathrm{BPD} \times$ diabetes & 0.055 & 0.817 & \\
\hline
\end{tabular}

Power analysis was computed using $\alpha=0.05$

${ }^{\text {a }}$ Significant $p$ values

As predicted by the model, GLP1 levels remained above the mesor between 16:48 and 19:04 hours in NGT participants before BPD, remaining almost similar after BPD; similar data were observed for GIP levels. Contrarily, in diabetic participants GLP1 levels remained above the mesor between 04:21 and 11:33 hours before BPD, and subsequently they shifted between 09:01 and 14:17 hours. In the same participants, GIP levels were above the mesor from 11:14 to $16: 38$ hours before BPD and from 08:15 to 14:29 hours after BPD.

Therefore, malabsorptive bariatric surgery had a strong influence on the rhythmicity of both GLP1 and GIP in type
2 diabetic participants, as shown in Fig. 2. After surgery the amplitude of the periodical components of the GIP time series was lower, suggesting a reduction in fluctuation around the mean level. The opposite was true for GLP1.

As shown in Table 3, which summarises the results of the two-way ANOVA, the BPD operation significantly influenced the reduction in the GIP AUC, although the combined action of BPD and diabetes had a larger effect on this change. The effect of BPD on the increase in the GLP1 AUC was significant, contrary to the effect of the factor diabetes alone; both factors, i.e. the combined effect of BPD and diabetes was stronger than that of BPD or diabetes individually. In contrast, the only factor affecting the insulin AUC value (from $6,524 \pm 1,175$ to $3,112 \pm$ $987.9 \mathrm{pmol} \mathrm{l}^{-1} \mathrm{~min}$ in NGT participants and from 4,804 \pm 799 to $2,004 \pm 584 \mathrm{pmol}^{-1} \mathrm{~min}$ in diabetic patients) was represented by BPD.

The overall $F$ value for the multivariate analysis model, whose variables are reported in Tables 4 and 5, was 2.27 ( $p=0.002$ ). Using $\eta^{2}$ as the measure of effect size, the interaction between BPD and diabetes accounted for $46 \%$ of the total variability of the dependent variables (insulin sensitivity, GIP AUC and GLP1 AUC).

\section{Discussion}

The principal findings of this study are that: (1) GIP and GLP1 showed a circadian rhythm in both glucose-tolerant and diabetic, morbidly obese participants; (2) the GLP1 AUC significantly increased after BPD in NGT but not in diabetic participants; (3) the GIP AUC significantly diminished in diabetic patients, with a large combined effect of BPD and diabetes; (4) GLP1 levels remained above the mesor earlier during the day in diabetic patients than in NGT participants; (5) the circadian rhythm of incretin was shifted in time after BPD only in diabetic participants; (6) the interaction between BPD and diabetes accounted for $46 \%$ of the total variability of insulin sensitivity, GIP AUC and GLP1 AUC; (7) all the above changes happened independently of any significant modification of body weight, since the participants were studied a very short time after the operation.

Ultradian fluctuations in GLP1 secretion have been detected in young healthy men [22], suggesting the
Table 4 Summary of multivariate analyses

Design: intercept $+\mathrm{BPD}+\mathrm{DIAB}$ $+\mathrm{BPD} \times \mathrm{DIAB}$

\begin{tabular}{lcccc}
\hline Effect & Pillai's trace value & $F$ value & $p$ value & Partial $\eta^{2}$ \\
\hline Intercept & 0.99 & 595.40 & 0.000 & 0.99 \\
BPD & 0.91 & 79.05 & 0.000 & 0.91 \\
Diabetes & 0.26 & 1.69 & 0.216 & 0.27 \\
BPD $\times$ diabetes & 0.46 & 3.93 & 0.032 & 0.46 \\
\hline
\end{tabular}


Table 5 Multivariate analysis for between-participant effects
${ }^{\text {a }} R^{2}=0.907$ (adjusted $R^{2}=$ 0.889 ); ${ }^{\mathrm{b}} R^{2}=0.020$ (adjusted $\left.R^{2}=-0.164\right) ;{ }^{\mathrm{c}} R^{2}=0.612$ (adjusted $R^{2}=0.540$ )

\begin{tabular}{|c|c|c|c|c|c|c|}
\hline Source & $\begin{array}{l}\text { Dependent } \\
\text { variable }\end{array}$ & $\begin{array}{l}\text { Type III sum } \\
\text { of squares }\end{array}$ & Mean square & $F$ value & $p$ value & Partial $\eta^{2}$ \\
\hline \multirow{3}{*}{$\begin{array}{l}\text { Corrected } \\
\text { model }\end{array}$} & $M$ value & $47.93^{\mathrm{a}}$ & 15.98 & 51.93 & 0.000 & 0.907 \\
\hline & GLP1 AUC & $12.92^{\mathrm{b}}$ & 4.30 & 0.11 & 0.954 & 0.020 \\
\hline & GIP AUC & $1,425.56^{\mathrm{c}}$ & 475.19 & 8.43 & 0.001 & 0.612 \\
\hline \multirow[t]{3}{*}{ Intercept } & $M$ value & 407.4 & 407.40 & $1,324.08$ & 0.000 & 0.988 \\
\hline & GLP1 AUC & $11,883.68$ & $11,883.68$ & 297.36 & 0.000 & 0.949 \\
\hline & GIP AUC & $11,719.91$ & $11,719.91$ & 207.81 & 0.000 & 0.929 \\
\hline \multirow[t]{3}{*}{ BPD } & $M$ value & 47.59 & 47.59 & 154.67 & 0.000 & 0.906 \\
\hline & GLP1 AUC & 12.66 & 12.66 & 0.32 & 0.581 & 0.019 \\
\hline & GIP AUC & 487.03 & 487.03 & 8.64 & 0.010 & 0.351 \\
\hline \multirow[t]{3}{*}{ Diabetes } & $M$ value & 0.37 & 0.37 & 1.19 & 0.292 & 0.069 \\
\hline & GLP1 AUC & 0.02 & 0.02 & 0.00 & 0.983 & 0.000 \\
\hline & GIP AUC & 251.76 & 251.76 & 4.46 & 0.051 & 0.218 \\
\hline \multirow[t]{3}{*}{$\mathrm{BPD} \times$ diabetes } & $M$ value & 0.02 & 0.02 & 0.06 & 0.817 & 0.003 \\
\hline & GLP1 AUC & 0.19 & 0.19 & 0.00 & 0.946 & 0.000 \\
\hline & GIP AUC & 706.07 & 706.07 & 12.52 & 0.003 & 0.439 \\
\hline \multirow[t]{3}{*}{ Error } & $M$ value & 4.92 & 0.31 & & & \\
\hline & GLP1 AUC & 639.43 & 39.96 & & & \\
\hline & GIP AUC & 902.35 & 56.40 & & & \\
\hline \multirow[t]{3}{*}{ Total } & $M$ value & 465.72 & & & & \\
\hline & GLP1 AUC & $12,776.92$ & & & & \\
\hline & GIP AUC & $14,529.76$ & & & & \\
\hline \multirow[t]{3}{*}{ Corrected total } & $M$ value & 52.85 & & & & \\
\hline & GLP1 AUC & 652.35 & & & & \\
\hline & GIP AUC & $2,327.91$ & & & & \\
\hline
\end{tabular}

possibility that these fluctuations might regulate insulin oscillations in secretion rate. In the present study we have demonstrated for the first time the presence of incretin circadian rhythms also in morbidly obese participants with either normal glucose tolerance or type 2 diabetes. After the operation, GLP1 secretion, which was basally higher in NGT participants than in diabetic patients, increased significantly only in the NGT group. In contrast, GIP secretion was significantly reduced after BPD in patients with type 2 diabetes but not in NGT participants. The BPD operation also changed the circadian rhythms of incretins by shifting them in time to earlier during the day.

In our series, $46 \%$ of the variation in insulin sensitivity, GIP and GLP1 was explained by the interaction between the BPD operation and the presence of diabetes.

Insulin-resistant diabetes, either in experimental animal models or in humans [23, 24], is associated with high circulating GIP levels secondary to an exaggerated $\mathrm{K}$ cell secretory response to nutrients. The findings of Flatt and colleagues $[23,25,26]$ in rodents provide an interesting parallelism with our results in humans. Genetic knockout of the GIP receptor and blockade of GIP action were both associated with a large improvement in insulin resistance and diabetes $[25,26]$.

BPD bypasses a large area of the small intestine, including the duodenum, jejunum and the major part of the ileum, and allows nutrients to enter directly the last part of the ileum. Although a diverse anatomical modification of the small intestine takes place in the Roux-en-Y gastric bypass (RYGB), in which the stomach is anastomosed with the jejunum a few centimetres after Treitz's ligament, the effects of BPD and RYGB in terms of GIP suppression in diabetic patients seem to be comparable. After gastric bypass, Rubino et al. [10] found that GIP decreased to normal levels in diabetic patients, whereas it increased slightly but not significantly in obese non-diabetic patients. This similarity might depend on the distribution of GIPsecreting $\mathrm{K}$ cells, which are present in both the duodenum and the jejunum [27].

The role of GIP in inducing glucose intolerance and insulin resistance is supported by the evidence [28] that GIP receptor antagonism by (Pro(3))GIP[mPEG], a mPEGylated 
antagonist of gastric inhibitory polypeptide, improves glucose tolerance and insulin secretory responses in both dietary and genetic diabesity.

In contrast, the effect of RYGB on GLP1 is quite different from that of BPD. After RYGB, an increase in the GLP1 level after OGTT or a meal was observed in people with NGT [14] and in diabetic patients [12, 13], and was associated with increased circulating levels of insulin.

While the diverse behaviours of the two types of bariatric surgery in terms of incretin secretion might be attributable to the bypass of different parts of the small intestine, the different effect of the same BPD operation in NGT and in type 2 diabetic participants requires further investigation.

Recently, an 'anti-incretin' theory has been postulated by Rubino [29], i.e. the existence of a counter-regulatory mechanism with opposite actions to those of incretins. According to this idea, this intestinal factor, which sustains GIP secretion, might be suppressed after BPD as a consequence of nutrient diversion.

In conclusion, the effect of BPD on the $24 \mathrm{~h}$ pattern of incretins differed markedly between NGT participants and patients with type 2 diabetes. Impairment of GLP1 secretion was reversed in NGT participants but could not be overcome by BPD in patients with diabetes. Contrarily, GIP secretion was blunted after the operation only in diabetic patients, suggesting a role of this incretin in insulin resistance and diabetes.

Duality of interest The authors declare that there is no duality of interest associated with this manuscript.

\section{References}

1. Vilsbøll T, Holst JJ (2004) Incretins, insulin secretion and type 2 diabetes mellitus. Diabetologia 47:357-366

2. Nauck M, Heimesaat MM, Orskov C, Holst JJ, Ebert R, Creutzfeldt W (1993) Preserved incretin activity of glucagonlike peptide 1 [7-36 amide] but not of synthetic human gastric inhibitory polypeptide in patients with type-2 diabetes mellitus. J Clin Invest 91:301-307

3. Nauck M, Stöckmann F, Ebert R, Creutzfeldt W (1986) Reduced incretin effect in type 2 (non-insulin-dependent) diabetes. Diabetologia 29:46-52

4. Zimmet P, Alberti KG, Shaw J (2001) Global and societal implications of the diabetes epidemic. Nature 414:782-787

5. Leibson CL, Williamson DF, Melton LJ 3rd et al (2001) Temporal trends in BMI among adults with diabetes. Diabetes Care 24:1584-1589

6. Golay A, Ybarra J (2005) Link between obesity and type 2 diabetes. Best Pract Res Clin Endocrinol Metab 19:649-663

7. Muscelli E, Mari A, Casolaro A et al (2008) Separate impact of obesity and glucose tolerance on the incretin effect in normal subjects and type 2 diabetic patients. Diabetes 57:1340 1348

8. Anderson JW, Grant L, Gotthelf L, Stifler LT (2006) Weight loss and long-term follow-up of severely obese individuals treated with an intense behavioral program. Int J Obes 31:488-493

9. MacDonald KG, Long SD, Swanson MS et al (1997) The gastric bypass operation reduces the progression and mortality of NIDDM. J Gastrointest Surg 1:213-220

10. Rubino F, Gagner M, Gentileschi P et al (2004) The early effect of the Roux-en-Y gastric bypass on hormones involved in body weight regulation and glucose metabolism. Ann Surg 240:236242

11. Guidone C, Manco M, Valera-Mora E et al (2006) Mechanisms of recovery from type 2 diabetes after malabsorptive bariatric surgery. Diabetes 55:2025-2031

12. Laferrère B, Teixeira J, McGinty $J$ et al (2008) Effect of weight loss by gastric bypass surgery versus hypocaloric diet on glucose and incretin levels in patients with type 2 diabetes. J Clin Endocrinol Metab 93:2479-2485

13. Laferrère $B$, Heshka $S$, Wang $K$ et al (2007) Incretin levels and effect are markedly enhanced 1 month after roux-en-Y gastric bypass surgery in obese patients with type 2 diabetes. Diabetes Care 30:1709-1716

14. Rodieux F, Giusti V, D’Alessio DA, Suter M, Tappy L (2008) Effects of gastric bypass and gastric banding on glucose kinetics and gut hormone release. Obesity 16:298-305

15. Pories WJ, Albrecht RJ (2001) Etiology of type II diabetes mellitus: role of the foregut. World J Surg 25:527-531

16. Mingrone G, DeGaetano A, Greco AV et al (1997) Reversibility of insulin resistance in obese diabetic patients: role of plasma lipids. Diabetologia 40:599-605

17. Camastra S, Manco M, Mari A et al (2007) Beta-cell function in severely obese type 2 diabetic patients: long-term effects of bariatric surgery. Diabetes Care 30:1002-1004

18. Mari A, Manco M, Guidone C et al (2006) Restoration of normal glucose tolerance in severely obese patients after bilio-pancreatic diversion: role of insulin sensitivity and beta cell function. Diabetologia 49:2136-2143

19. DeFronzo RA, Tobin JD, Andres R (1979) Glucose clamp technique: a method for quantifying insulin secretion and resistance. Am J Physiol 237:E214-E223

20. Krarup T, Madsbad S, Moody AJ et al (1983) Diminished gastric inhibitory polypeptide (GIP) response to a meal in newly diagnosed type I (insulin dependent) diabetics. J Clin Endocrinol Metab 56:1306-1312

21. Ørskov C, Rabenhøj L, Kofod H, Wettergren A, Holst JJ (1994) Production and secretion of amidated and glycineextended glucagon-like peptide-1 (GLP-1) in man. Diabetes 43:535-539

22. Simon C, Brandenberger G (2002) Ultradian oscillations of insulin secretion in humans. Diabetes 51:S258-S261

23. Flatt PR, Bailey CJ, Kwasowski P, Page T, Marks V (1984) Plasma immunoreactive gastric inhibitory polypeptide in obese hyperglycaemic (ob/ob) mice. J Endocrinol 101:249-256

24. Vilsbøll T, Krarup T, Sonne J et al (2003) Incretin secretion in relation to meal size and body weight in healthy subjects and people with type 1 and type 2 diabetes mellitus. J Clin Endocrinol Metab 88:2706-2713

25. McClean PL, Irwin N, Cassidy RS, Holst JJ, Gault VA, Flatt PR (2007) GIP receptor antagonism reverses obesity, insulin resistance, and associated metabolic disturbances induced in mice by prolonged consumption of high-fat diet. Am J Physiol Endocrinol Metab 293:E1746-E1755

26. Gault VA, Irwin N, Green BD et al (2005) Chemical ablation of gastric inhibitory polypeptide receptor action by daily (Pro3)GIP administration improves glucose tolerance and ameliorates insulin 
resistance and abnormalities of islet structure in obesity-related diabetes. Diabetes 54:2436-2446

27. Damholt AB, Kofod H, Buchan AM (1999) Immunocytochemical evidence for a paracrine interaction between GIP and GLP-1producing cells in canine small intestine. Cell Tissue Res 298:287-293
28. McClean PL, Irwin N, Hunter K, Gault VA, Flatt PR (2008) (Pro (3))GIP[mPEG]: novel, long-acting, mPEGylated antagonist of gastric inhibitory polypeptide for obesity-diabetes (diabesity) therapy. Br J Pharmacol 155:690-701

29. Rubino F (2008) Is type 2 diabetes an operable intestinal disease? A provocative yet reasonable hypothesis. Diabetes Care 31:S290-S296 